\title{
Pengembangan Ekstrak Etanol Buah Pepino (Solanum Muricatum Aiton) dalam Bentuk Granul Effervescent dengan Variasi Bahan Pengikat
}

\section{(Development of Pepino Fruit (Solanum muricatum Aiton) Ethanol Extract In The Form of Effervescent Granules with Various Binding Materials)}

\author{
Hamsinah $^{1 *}$, Ririn $^{1}$

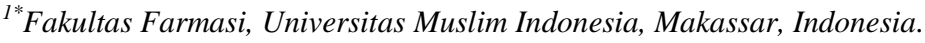 \\ E-mail: hamsinah.hamsinah@umi.ac.id \\ Article Info: \\ Received: 03 Maret 2019 \\ in revised form: 31 Januari 2020 \\ Accepted: 06 maret 2020 \\ Available Online: 07 Maret 2020

\section{Keywords:} \\ Ethanol Extract \\ Pepino Fruit \\ PVP K30 \\ Effervescent Granules \\ Corresponding Author: \\ Hamsinah \\ Fakultas Farmasi \\ Universitas Muslim Indonesia \\ Makassar \\ 90231 \\ Indonesia \\ email: \\ hamsinah.hamsinah@umi.ac.id

\begin{abstract}
Pepino fruit (Solanum muricatum Aiton) is an edible fruit, the fruit that can be picked is watery, fragrant is slightly sweet and has a very varied shape and color. Pepino has a high percentage of water content, low in calories, very rich in minerals and contain vitamins such as thiamine, niacin, riboflavin, and ascorbic acid. The aim of the investigation is to obtain a good preparations of effervescent granules of ethanol extract of pepino fruit (Solanum muricatum Aiton) based on parameter of flowability and repose angle, density, moisture content, loss on drying and dispersibility. Maceration method and ethanol $96 \%$ as the solvent is use to obtain the extract of pepino fruit (Solanum muricatum Aiton). There are three formula design of effervescent granules formula 1, 2 and 3 each of which in variation of binder PVP K30 2\%, 4\% and $6 \%(\mathrm{w} / \mathrm{w})$. The granules is obtain by wet granulation method in which ethanol extract of pepino fruit as the active ingredient. Results of evaluation showed that angle of repose range from $33.42^{\circ}-34.35^{\circ}$ while flowability range from $5.84-6.66 \mathrm{~g} / \mathrm{second}$. Bulk density range from $0.519-0.570 \mathrm{~g} / \mathrm{ml}$, tap density $0.552-0.53 \mathrm{~g} / \mathrm{ml}$, true density $0.2005-1.22 \mathrm{~g} / \mathrm{ml}$. Uji porositas berkisar 6.36-44.609 \% while the dispersibility range from 1.407-1.477 gram/second. Based on the results can be concluded that all granules possess good properties pharmaceutically.
\end{abstract}

Copyright (C) 2019 JFG-UNTAD

This open access article is distributed under a Creative Commons Attribution (CC-BY-NC-SA) 4.0 International license.

How to cite (APA $6^{\text {th }}$ Style):

Hamsinah, \& Ririn. (2020). Pengembangan Ekstrak Etanol Buah Pepino (Solanum Muricatum Aiton) dalam Bentuk Granul Effervescent dengan Variasi Bahan Pengikat. Jurnal Farmasi Galenika: Galenika Journal of Pharmacy (e-Journal), 6(1), 124-131. doi:10.22487/j24428744.2020.v6.i1.12037 


\section{ABSTRAK}

Buah Penino (Solanum muricatum Aiton) merupakan buah yang yang dapat dimakan, buah yang dapat dipetik yang berair, wangi sedikit manis, dan memiliki bentuk dan warna yang sangat bervariasi. Pepino memiliki persentase kadar air yang tinggi, rendah kalori, sangat kaya akan mineral dan mengandung vitamin seperti tiamin, niasin, riboflavin, dan asam askorbat. Penelitian ini bertujuan untuk memperoleh sediaan formula granul effervescent yang baik berdasarkan parameter organoleptis, kecepatan alir dan sudut diam, densitas, uji kadar air, uji kemampuan dispersi. Ekstrak etanol buah pepino (Solanum muricatum Aiton) diperoleh dengan metode maserasi menggunakan pelarut etanol $96 \%$. Dalam penelitian ini dibuat tiga rancangan formulasi granul effervescent formula 1, 2 dan 3 dengan variasi bahan pengikat PVP K30 menggunakan metode granulasi basah dengan ekstrak etanol buah pepino (Solanum muricatum) sebagai zat aktif. Kemudian dilakukan evaluasi yang meliputi uji kecepatan alir dan sudut diam, densitas, uji kadar air, uji kemampuan dispersi. Hasil penelitian menunjukkan uji sudut diam berkisar $33,42^{\circ}-34,35^{\circ}$ sedangkan kecepatan alir berkisar 5,84-6,66 g/detik. Densitas bulk berkisar dari 0,519-0,570 g/ml, densitas mampat 0,552-0,53 g/ml, densitas sejati 0,2005-1,22 g/ml. Uji porositas berkisar 6,36-44,609 \% sedangkan uji kecepatan terdispersi berkisar 1,407-1,477 gram/detik. Dari hasil yang diperoleh dapat disimpulkan bahwa semua formula memiliki sifat farmaseutika yang baik.

Kata kunci: Ekstrak etanol pepino (Solanum muricatum Aiton), PVP K30, Granul Effervescent

\section{PENDAHULUAN}

Pepino (Solanum muricatum Aiton) merupakan tumbuhan sepanjang tahun pada daerah yang sedang dari pegunungan Andes Kolombia, peru dan Chili. Buah pepino (Solanum muricatum Aiton) merupakan buah yang dapat dimakan, buah yang dapat dipetik yang berair, wangi, sedikit manis dan memiliki bentuk dan warna yang sangat bervariasi (IPGRI \& COMAV, 2004). Kata pepino berasal dari bahasa Spanyol yang berarti "mentimum" karena kesamaan rasa dan tekstur antara keduanya (Prohens et al., 1989). Pepino memiliki persentase kadar air yang tinggi (92\%), rendah kalori, sangat kaya akan mineral dan mengandung vitamin seperti tiamin, niasin, riboflavin dan asam askorbat (vitamin C), ideal untuk sejumlah metabolik dan reaksi antioksidan (Diaz, 2006).

Hasil penelitian dari Sudha et al., 2012 menunjukkan bahwa buah pepino matang memperlihatkan aktivitas antioksidan yang tinggi dalam semua pengujian peredaman kecuali untuk pengujian peredamaan radikal hidroksil. Nilai $\mathrm{EC}_{50}$ dari ekstrak etanol pepino matang terhadap radikal DPPH, kekuatan mereduksi, kelas ion ferrat, radikal ABTS, FRAP, radikal hidroksil, peroksidasi lipid (otak) dan peroksidasi lipid (hati) adalah 2,20; $2.81 ;<5,00 ; 34,06 ; 8,53 ; 1,30 ; 1,75$ dan 0,51 mg/mL. Pepino matang memiliki kandungan total fenol dan flavonoid yang lebih tinggi dibanding buah pepino yang tidak matang. Hasil studi tersebut menunjukkan bahwa kemungkinan mekanisme aktivitas biologi mungkin disebabkan karena sifat meredam radikal bebas dan sifat antioksidan.

Salah satu bentuk sediaan yang dapat digunakan untuk menghantarkan bahan antioksidan adalah granul effervescent. Granul effervescent adalah bentuk sediaan padat dari bahan obat yang ditujukan untuk penggunaan internal. Granul effervescent mengandung asam sitrat, tartarat dan natrium bikarbonat. Keuntungan dari granul effervescent adalah cepat melarut, merupakan bentuk sediaan yang sangat larut, nyaman dan stabil. Ketika berkontak dengan air granul cepat terdispersi membebaskan karbondioksida disebabkan karena interaksi antara asam dengan logam alkali karbonat atau bikarbonat. Keuntungan lain dari sediaan ini dibanding bentuk sediaan oral lainnya adalah kemudahan formulator untuk memperbaiki rasa, aksi yang lebih lembut pada perut pasien dan aspek pemasaran

Berdasarkan hal tersebut di atas, maka dilakukan formulasi granul effervescent dari ekstrak etanol buah pepino (Solanum muricatum Aiton) sebagai suplemen antioksidan dengan melakukan optimasi bahan pengikat (binder) dan beberapa evaluasi sediaan granul meliputi parameter organoleptis, kecepatan alir dan sudut diam, densitas, uji kadar air, uji kemampuan dispersi dan aktivitas dalam bentuk sediaan sehingga, diperoleh sediaan granul yang baik dan memiliki aktivitas antioksidan yang optimal. 


\section{METODE PENELITIAN}

\section{Alat dan Bahan}

Alat-alat yang digunakan adalah alat-alat gelas yang digunakan dalam analisis alat pengujian Tap Density, Vibrator Shaker (Roche), Oven (Memmert), Piknometer, Mesh 16 (Roche), Beaker glass (Pyrex), corong, lumping dan alu, timbangan analitik (Ohauss). Bahan-bahan yang digunakan adalah air suling, etanol 96\%, buah pepino (Solanum muricatum Aiton), methanol p.a, serbuk kunyit, polivinilpirilidon (PVP) K30, paraffin cair, asam sitrat, asam tartrat, natrium bikarbonat, dan aspartam.

\section{Metode Penyiapan Ekstrak Etanol Buah Pepino (Solanum muricatum Aiton)}

Sampel yang digunakan adalah buah pepino (Solanum muricatum Aiton) segar. Buah pepino yang telah dibersihkan dipotong-potong kecil dan dikeringkan dengan cara dikeringkan dalam oven pada suhu $60^{\circ} \mathrm{C}$, selama 3 hari. Sampel buah pepino kering kemudian dimaserasi dengan menggunakan etanol (96\%) selama 3 hari sambal sesekali diaduk. Sampel disaring dan diuapkan untuk memperoleh ekstrak kentalnya. Selanjutnya ekstrak kental yang diperoleh digunakan dalam formulasi sediaan granul effervescent.

Rancangan Formula Granul Effervescent Ektsrak Etanol Buah Pepino (Solanum muricatum Aiton)

Rancangan formula granul effervescent ekstrak etanol buah pepino (Solanum muricatum Aiton) terdiri dari esktrak buah pepino (Solanum muricatum Aiton) sebagai bahan aktif antioksidan, PVP K30 sebagai pengikat, asam sitrat dan asam tartarat sebagai sumber asam, natrium bikarbonat sebagai sumber basa, aspartame sebagai pemanis dan kunyit sebagai pewarna alami.

\section{Pembuatan Granul Effervescent Ektsrak Etanol Buah Pepino (Solanum muricatum Aiton)}

Metode pembuatan granul effervescent ekstrak etanol buah pepino (Solanum muricatum Aiton) menggunakan metode granulasi basah. Asam sitrat, asam tartarat digerus secara terpisah hingga menjadi serbuk. Masing-masing disimpan dalam wadah yang terpisah. Ekstrak buah pepino (Solanum muricatum Aiton) dimasukkan kedalam lumpang kemudian ditambahkan aspartam sebagai pemanis dan ditambahkan PVP K30 dan kunyit, digerus hingga homogen. Setelah itu di tambahkan natrium bikarbonat pada campuran tersebut dibuat granul dengan cara ditambahkan air sebagai bahan pelembab hingga campuran serbuk menjadi adonan yang mudah dikepal. Kemudian ditambahkan asam tartarat dan sitrat, digerus hingga homogen. Massa lembab kemudian diayak basah menggunakan mesh 16 di atas aluminium foil dan dilakukan penimbangan masa lembab. Granul kemudian dikeringkan pada suhu $60^{\circ} \mathrm{C}$ selama 24 jam sambil sesekali diaduk. Granul kering kemudian ditimbang dan diayak menggunakan mesh 16 . Setelah itu dilakukan evaluasi granul.

\section{Evaluasi Granul Effervescent Ektsrak Etanol Buah Pepino (Solanum muricatum Aiton)}

\section{Densitas Bulk}

Granules effervescent dimasukkan kedalam gelas ukur $50 \mathrm{ml}$, tanpa memampatkan. Volume serbuk kemudian dicatat sebagai volume nyata, Vo. Densitas bulk kemudian dihitung menggunakan rumus berikut:

$$
\mathbf{\rho b}=\mathbf{M} / \mathbf{V o}
$$

Dimana, $\rho \mathrm{b}=$ densitas bulk nyata, $\mathrm{M}=$ berat sampel, $\mathrm{V}=$ volume nyata serbuk.

(Aulton, 2006) 


\section{Densitas mampat}

Setelah melakukan prosedur pada densitas bulk, maka gelas ukur yang mengandung sampel dimampatkan sebanyak 500 kali dan kemudian dicatat volume mampat, Vf. Densitas mampat, dalam gram per ml kemudian dihitung dengan menggunakan rumus berikut :

$$
\rho \operatorname{tap}=\mathbf{M} / \mathbf{V f}
$$

Dimana, $\rho$ tap $=$ densitas mampat, $\mathrm{M}=$ berat sampel, $\mathrm{Vf}=$ volume mampat serbuk.

(Aulton, 2006).

\section{Carr's Index (\%)}

Indeks kompressibilitas (Carr's index) adalah pengukuran propensitas serbuk untuk dikempa. Carr's index ditentukan dari densitas bulk dan densitas mampat. Secara teori, semakin kurang serbuk dapat dikempa semakin dapat mengalir sutau serbuk. Dengan demikian, Carr's index mengukur pentingnya interaksi antarpartikel. Untuk serbuk yang bebas mengalir, interaksi tersebut pada umumnya kurang signifikan, dan nilai densitas bulk dan mampat akan berdekatan. Untuk bahan yang alirannya buruk, seringkali terjadi interaksi antarpartikel yang lebih besar, dan nilai densitas bulk dan densitas mampat akan jauh berbeda. Perbedaan nilai tersebut akan tergambarkan pada nilai Carr's index yang dihitung menggunakan rumus :

\section{Indeks kompresibilitas $=[(\rho \operatorname{tap}-\rho b) / \rho \operatorname{tap}] / \times 100$}

Dimana, $\rho \mathrm{b}=$ Densitas bulk, $\rho$ tap $=$ Densitas mampat

Hausner's ratio adalah indeks tidak langsung dari kemudahan aliran serbuk. Hausner's ratio dapat dihitung menggunakan rumus:

\section{Hausner's Ratio $=$ densitas mampat $(\rho t) /$ densitas bulk $(\rho b)$}

Dimana $\rho t$ densitas mampat and $\rho b$ adalah densitas bulk. Semakin rendah nilai Hausner's ratio $(1,25)$ menunjukkan sifat aliran yang baik dibanding dengan nilai yang lebih tinggi, antara 1,25-1,5 menunjukkan sifat aliran moderat dan lebih dari 1,5 menunjukkan aliran yang buruk (Aulton, 2006).

Tabel 1. Nilai indeks kompresibilitas

\begin{tabular}{cc}
\hline Indeks Kompressibilitas & Sifat Aliran \\
\hline$\leq 10$ & Baik sekali \\
\hline $11-15$ & Baik \\
\hline $16-20$ & Sedang \\
\hline $21-25$ & Passable \\
\hline $26-31$ & Buruk \\
\hline $32-37$ & Sangat buruk \\
\hline$\geq 38$ & Sangat sangat buruk \\
\hline
\end{tabular}




\section{Sudut diam}

Fixed funnel method digunakan untuk mengukur sudut diam. Corong ditutup pada bagian ujungnya pada ketinggian tertentu (h), sedangkan pada bagian bawah diletakkan kertas grafik. Granul kemudian dimasukkan kedalam corong dan dibiarkan mengalir hingga bagian atas gundukan serbuk menyentuh ujung corong. Radius dasar gundukan diukur. Sudut diam $(\theta)$ dihitung menggunakan rumus berikut:

\section{$\operatorname{Tan} \theta=\mathbf{h} / \mathbf{r}$}

Dimana, $\theta=$ sudut diam, $\mathrm{h}=$ ketinggian gundukan, $\mathrm{r}=$ radius dari dasar gundukan.

Nilai untuk sudut diam $\leq 30^{\circ}$ biasanya menunjukkan bahan bebas mengalir dan sudut diam $\geq 40^{\circ}$ menunjukkan bahan yang memiliki aliran yang buruk, 25-30 menunjukkan sifat aliran yang paling baik, 31-35 menunjukkan sifat aliran yang baik, 36-40 menunjukkan sifat aliran yang cukup dan 4145 menunjukkan sifat aliran passable (Aulton, 2006).

\section{Effervescent Cessation Time}

Sebanyak $200 \mathrm{ml}$ air suling dimasukkan kedalam gelas kimia $250 \mathrm{ml}$, sebanyak 2 gram dari granul effervescent dimasukkan ke dalam gelas kimia kemudian diamati waktu terjadinya buih hingga waktu berhenti buih (Aulton, 2006).

Tabel 2. Rancangan Formula Granul Effervescent

\begin{tabular}{clccc}
\hline \multirow{2}{*}{ No Nama Bahan } & \multicolumn{3}{c}{ Formula } \\
\cline { 3 - 5 } & & F 1 & F 2 & F 3 \\
\hline 1. & Ekstrak etanol buah Pepino $(\mathrm{mg} / \mathrm{ml})$ & 2,20 & 2,20 & 2,20 \\
\hline 2. & PVP K30 & 2 & 4 & 6 \\
\hline 5. & Aspartam & 0,001 & 0,001 & 0,001 \\
\hline 6. & Curcumin & 0,001 & 0,001 & 0,001 \\
\hline 7. & Asam sitrat & 1 & 1 & 1 \\
\hline 8. & Asam tartarat & 2 & 2 & 2 \\
\hline 9. & Na bikarbonat & 3,4 & 3,4 & 3,4 \\
\hline
\end{tabular}

Catatan: satuan konsentrasi dalam $b / b$ dan perbandingan sumber asam dan basa $(1: 2: 3,4)$

\section{HASIL DAN PEMBAHASAN}

Pemanfaatan bahan alam sebagai alternatif pengobatan belakangan sangat marak dilakukan. Penggunaan bahan alam memiliki keuntungan selain bersumber dari alam, efek samping yang ditimbulkan sangat kecil. Formulasi bahan alam menjadi bentuk sediaan modern dibutuhkan untuk meningkatkan efektivitas dan estetika dari bahan alam tersebut. Sediaan granul dari ekstrak etanol buah pepino (Solanum muricatum Aiton) dibuat untuk menghasilkan sediaan berbasis bahan alam dengan pendekatan sediaan modern. Salah satu komponen yang berpengaruh terhadap sediaan granul tersebut adalah bahan pengikat. Penelitian ini bertujuan untuk melihat perbedaan konsentrasi pengikat dapat mempengaruhi sifat farmaseutik dari granul effervescent yang dibuat.

Densitas didefenisikan sebagai berat per unit volume. Density bulk, $\rho b$, didefenisikan sebagai berat serbuk dibagi dengan volum bulk dan dinyatakan dalam $\mathrm{gm} / \mathrm{cm}^{3}$. Densitas bulk serbuk atau granul bergantung pada distribusi ukuran partikel, bentuk partikel dan kecenderungan partikel untuk saling melekat satu sama lain. Densitas bulk sangat penting dalam menentukan ukuran wadah yang dibutuhkan selama penanganan, pengapalan, dan penyimpanan bahan baku dan campuran. Densitas bulk juga penting dalam ukuran peralatan pencampuran. Densitas bulk dari semua formula (tabel 4) memperlihatkan bahwa semua formula memiliki densitas bulk yang rendah dan dapat diasumsikan 
bahwa granul effervescent yang dihasilkan membutuhkan wadah yang lebih kecil. Sedangkan densitas mampat (tabel 5) memiliki nilai hampir sama dengan densitas bulk kecuali pada formula 3.

Kedekatan nilai antara densitas bulk dan densitas mampat menunjukkan bahwa interaksi antarpartikel kurang terjadi. Kedekatan nilai tersebut akan terlihat ada nilai dari indeks kompresibilitas (Carr's index). Jika interaksi antarpartikel besar maka akan mempengaruhi laju alir granul sehingga mempengaruhi pengisian granul kedalam wadah.

Tabel 3. Hasil Ekstraksi

\begin{tabular}{ccc}
\hline Berat Buah Basah $\mathbf{( K g )}$ & Berat Buah Kering (g) & Berat Ekstrak (g) \\
\hline 5,613 & 117 & 77,618 \\
\hline
\end{tabular}

Tabel 4. Densitas Bulk granul effervescent

\begin{tabular}{cccc}
\hline Formula & Berat $(\mathbf{g})$ & Volume $(\mathbf{m L})$ & Densitas $(\mathbf{g} / \mathbf{m L})$ \\
\hline 1 & 25,09 & 50,0 & 0,50 \\
\hline 2 & 26,47 & 50,0 & 0,53 \\
\hline 3 & 28,49 & 50,0 & 0,57 \\
\hline
\end{tabular}

Tabel 5. Densitas mampat granul efffervescent

\begin{tabular}{cccc}
\hline Formula & Berat $(\mathbf{g})$ & Volume $(\mathbf{m L})$ & Densitas $(\mathbf{g} / \mathbf{m L})$ \\
\hline 1 & 25,09 & 50,0 & 0,53 \\
\hline 2 & 26,47 & 50,0 & 0,59 \\
\hline 3 & 28,50 & 50,0 & 0,65 \\
\hline
\end{tabular}

Indeks kompressibilitas (Carr's index) adalah pengukuran propensitas dari suatu serbuk atau granul yang akan dikempa. dari hasil penelitian diperoleh bahwa indeks kompresibilitas formula 1 dan 2 memiliki sifat aliran yang paling baik dengan indeks kompresibilitas $\leq 10$ sedangkan formula 3 memiliki sifat aliran yang baik dengan indeks kompresibilitas berada pada kisaran 11-15 (tabel 6). Sedangkan berdasarkan Hausner's ratio ketiga formula memiliki sifat aliran yang baik dengan nilai $<1,25$ (tabel 7).

Tabel 6. Indeks Kompressibilitas

\begin{tabular}{cccc}
\hline Formula & BJ Bulk (g/mL) & $\begin{array}{c}\text { BJ Mampat } \\
(\mathbf{g} / \mathbf{m L})\end{array}$ & $\begin{array}{c}\text { Indeks } \\
\text { kompressibilitas (\%) }\end{array}$ \\
\hline 1 & 0,52 & 0,53 & 1.9 \\
\hline 2 & 0,53 & 0,59 & 10 \\
\hline 3 & 0,57 & 0,65 & 12 \\
\hline
\end{tabular}

Tabel 7. Hausner's Ratio granules effervescent

\begin{tabular}{cccc}
\hline Formula & BJ Bulk $(\mathbf{g} / \mathbf{m L})$ & $\begin{array}{c}\text { BJ Mampat } \\
(\mathbf{g} / \mathbf{m L})\end{array}$ & $\begin{array}{c}\text { Hausner's } \\
\text { Ratio }\end{array}$ \\
\hline 1 & 0,52 & 0,53 & 1,02 \\
\hline 3 & 0,53 & 0,59 & 1,11 \\
\hline 3 & 0,57 & 0,65 & 1,14 \\
\hline
\end{tabular}

Tabel 8. Sudut Diam Granul Effervescent

\begin{tabular}{cccc}
\hline Formula & Diameter $(\mathbf{c m})$ & $\begin{array}{c}\text { Ketinggian } \\
\text { gundukan }(\mathbf{c m})\end{array}$ & $\begin{array}{c}\text { Sudut diam } \\
(\boldsymbol{\theta})\end{array}$ \\
\hline 1 & 10,43 & 3,5 & $34,35^{\circ}$ \\
\hline 2 & 10,4 & 3,4 & $34,45^{\circ}$ \\
\hline 3 & 10,0 & 3,3 & $33,42^{\circ}$ \\
\hline
\end{tabular}


Granul effervescent dievaluasi sudut diam, Hausner;s ratio, dan indeks kompresibilitas (Leiberman et al.,1994; Ansel et al.,1999). Sudut diam yang diperoleh pada penelitian ini pada semua formula mengindikasikan bahwa ketiga formula tersebut memiliki aliran yang baik (tabel 8). Berdasarkan nilai sudut diam, nilai 31-35 menunjukkan sifat aliran yang baik. Hal tersebut menunjukkan bahwa pada formulasi granul effervescent ekstrak etanol buah pepino (Solanum muricatum Aiton) tidak memerlukan penambahan glidant.

Tabel 9. Kecepatan terdispersi

\begin{tabular}{cc}
\hline Formula & Kecepatan dispersi (detik) \\
\hline 1 & 1,47 \\
\hline 2 & 1,41 \\
\hline 3 & 1,46 \\
\hline
\end{tabular}

Waktu berhenti buih dari ketiga formula menunjukkan perbedaan hasil yang tidak siknifikan (table 9). Hal ini berarti bahwa granul effervescent ekstrak etanol buah pepino (Solanum muricatum Aiton) tidak memerlukan waktu yang lama untuk melarut di dalam air. Pada proses pelarutan reaksi asam sitrat dan tartarat dengan natrium bikarbonat akan menghasilkan $\mathrm{CO}_{2}$ yang bekerja sebagai disintegan. Perbandingan sumber asam dan basa 1:2:3,4 merupakan perbandingan yang paling baik dalam reaksi pembentukan buih. Konsentrasi pengikat yang berbeda tidak mempengaruhi laju disperse dari granul effervescent yang dihasilkan.

\section{KESIMPULAN}

Semua formula granul effervescent ekstrak etanol buah pepino (Solanum americatum Aiton) memiliki sifat farmaseutik yang baik.

\section{UCAPAN TERIMAKASIH}

Penelitian ini dibiayai oleh Lembaga penelitian dan Pengembangan Sumber Daya (LP2S) Yayasan Wakaf Universitas Muslim Indonesia. 


\section{DAFTAR PUSTAKA}

Ansel, H. C., Popovich, N. G., Allen, L.V. (1999) Pharmaceutical Dosage Forms and Drug Delivery Systems. New Delhi: B. I. Waverly. 469-471.

Aulton, M. E. (2002). Pharmaceutics: The science of dosage form design ( $2^{\text {nd }}$ ed). Edinburgh: Churchill Livingstone.

Diaz, L. (2006). Industrialización y aprovechamiento de productos y subproductos derivados de materias primas agropecuarias de la región de Coquimbo (1st Edition). Santiago: LOM ediciones Ltda.

IPGRI \& COMAV. (2004). Descriptors for pepino (Solanum muricatum), International Plant Genetic Recources Institute, Rome, Italy and Centro de Conservacion y Mejora de la Agrodiversidad Valenciana, Valencia, Spain.

Lieberman, H. A., Lachman, L., Schwartz, J.B. (1994). Pharmaceutical Dosage Forms: Tablets, Vol.1 and 2. New York: Marcel Dekker Inc. 285.

Prohens, J., Ruiz, J. J., \& Nuez, F. (1996). The Pepino (Solanum muricatum, Solanaceae): A "New" Crop with a History. Economic Botany, 50(4), 355-368.

Sudha, G., Sangeetha P. M., Indhu, S. R. B., \& Vadivukkarasi, S. (2012). Antioxidant Activity of Ripe and Unripe Pepino Fruit (Solanum muricatum Aiton). Journal of Food Science, 77(11), C1131C1135. 